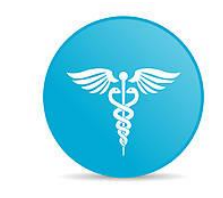

International Journal of Advances in Pharmacy and Biotechnology

Vol.1, Issue-1, 2015, 20-27

I J A P B

Research Article

Open Access

\title{
DEVELOPMENT AND EVALUATION OF TRANSDERMAL DRUG DELIVERY SYSTEM OF PROPRANOLOL HCI
}

\author{
*S. Ramkanth ${ }^{1}$, C. Madhusudhana Chetty ${ }^{2}$ and Y. Sudhakar ${ }^{3}$ \\ ${ }^{1}$ Annamacharya College of Pharmacy, Rajampet, Andhra Pradesh - 516 126, India. \\ ${ }^{2}$ Mahathi College of Pharmacy, Madhanapalli, Chittor (Dt.), Andhra Pradesh, India. \\ ${ }^{3}$ Government Polytechnic College for women, Kadapa, Andhra Pradesh, India.
}

*Corresponding author e-mail: ramkanthsg@gmail.com

\begin{abstract}
:
Administration of conventional tablets of Propranolol has been reported to exhibit fluctuations in the plasma drug levels, resulting either in manifestation of side effects such as diarrhea, ischemic colitis and mesenteric arterial thrombosis or reduction in drug concentration at the receptor site. Transdermal drug delivery (TDD) method has been selected as it provides controlled release of the drug, and produces a steady blood-level profile, leading to reduced systemic side effects and, sometimes, improved efficacy over other dosage forms. In the present work, efforts have been made to prepare transdermal drug delivery system of Propranolol using various blends of polymers such as Eudragit RS 100, Hydroxy propyl methyl cellulose K100M and Poly vinyl pyrrolidone using propylene glycol as a permeation enhancer. The prepared patches were evaluated for various physicochemical properties and in-vitro drug release studies. The drug release data was fitted to statistical approach such as Zero order kinetics, Higuchi's and Peppa's plot. The optimized formulation from the in-vitro drug release study is used to carry out in-vitro skin permeation study using porcine ear skin, snake shed skin and rat skin. The in-vivo evaluation of formulation F 7 (1.5 \% Eudragit RS 100, $1.5 \%$ HPMC $\mathrm{K} 100 \mathrm{M}$ ) shown better correlation with the in-vitro drug release which confirms the achievement of targets of the present study such as controlled prolonged zero order release, reduced frequency of administration, greater therapeutic effect, overcome the side effects, simplify the treatment regimen and thus may improve patient compliance.
\end{abstract}

Key words: Propranolol, Eudragit RS 100, HPMC K100M, Transdermal Patch, Zero order kinetics.

\section{INTRODUCTION:}

Propranolol (nonselective $\beta$-adrenoreceptor blocker) is widely used in the treatment of many cardiovascular diseases like hypertension, angina pectoris, cardiac arrhythmia and myocardial infarction. But propranolol exhibits an extensive and highly variable hepatic first pass metabolism following oral administration. So, its oral bioavailability was reported to be between 15 and $23 \%$. On oral administration, propranolol undergoes rapid and complete absorption from gastrointestinal tract, still the oral bioavailability is low (30\%) because of significant first pass hepatic metabolism by CYP2C19 and 2D61. To overcome these adverse effects in the GI tract while sustaining the therapeutic efficacy of Propranolol, an alternative drug delivery method might be useful $^{2}$. Transdermal drug delivery (TDD) method has been selected as it provides controlled release of the drug, and produces a steady blood-level profile ${ }^{3}$, leading to reduced systemic side effects and, sometimes, improved efficacy over other dosage forms 4 . In addition, it confers several advantages over

\section{How to cite this article:}

S. Ramkanth et. al., Development and evaluation of transdermal drug delivery system of propranolol HCl. Int. J. Adv. Pharm. Biotech., 2015; 1(1): 20-27. 
more traditional administration and leads to improved patient compliance. Consequently, the transdermal therapeutic system is of particular clinical significance for the prevention and long-term treatment of chronic diseases like hypertension ${ }^{5}$.

The aim of the present study was to investigate Propranolol transport from a transdermal patch system and to determine whether therapeutically relevant delivery rates could be achieved under these conditions. After an initial investigation of formulation parameters their effect on Propranolol transport across porcine ear skin, rat skin and snake shed skin was also investigated by in-vitro method. The sustained activity was due to the controlled release of drug into the systemic circulation following transdermal administration.

\section{MATERIALS AND METHODS Materials}

Propranolol was obtained as gift sample from Sun Pharmaceutical Industries Ltd. (India). Hydroxy propyl methyl cellulose (HPMC K100M), Poly vinyl pyrollidine (PVP K30), Eudragit RS 100 were purchased from Loba Chemie Ltd. (India). All other chemicals used for this study were of analytical grade.

\section{Preformulation Studies \\ Drug partition coefficient}

The partition co-efficient of the drug was determined using n-octanol: Phosphate buffer (pH 7.4) system. The n-octanol- Phosphate buffer partition coefficient serves as a parameter of lipophilicity. n-octanol and Phosphate buffer were presaturated with each other for at least $24 \mathrm{~h}$ before the experiment. An accurately weighed quantity of drug was dissolved in $10 \mathrm{ml}$ of n-octanol phase and shaken at $37^{\circ} \mathrm{C}$ for $24 \mathrm{~h}$ against 10 $\mathrm{ml}$ buffer in a sealed container. The separated n-octanol phase was assayed by UV spectroscopy to determine its residual concentration and hence the amount partitioned into the buffer6,7. The partition coefficient was expressed as the concentration of drug in the n-octanol phase $(\% \mathrm{w} / \mathrm{v})$ divided by the concentration in the aqueous phase.

\section{Drug-excipient interaction study}

The pure drug, Propranolol and a mixture of it with the polymers, HPMC K100M, PVP K30 and Eudragit RS 100 were mixed separately with IR grade $\mathrm{KBr}$ in the ratio of 100:1 and corresponding pellets were prepared by applying pressure in a hydraulic press ${ }^{8}$. The pellets were scanned over a wave number range of $4000-400 \mathrm{~cm}^{-1}$ in FTIR instrument (Shimadzu Japan).

\section{Fabrication of transdermal patches}

Transdermal patches composed of different polymers containing Propranolol were prepared by Solvent Casting technique as illustrated in Table 1. Firstly, drug was dissolved in ethanol. Base materials were added into the solution and swelled in ambient temperature. Permeation enhancers and plasticizer were added to the solution, and then agitated in a sonicator. This was casted on a glass surface containing ring, it was covered by funnel to control evaporation of solvent and allowed to dry at room temperature over night. The films were separated and the backing membrane used was aluminium foil and the formulations were stored in desiccator. After being dried, the single-layer patch was obtained ${ }^{9}$.

\section{Physico chemical evaluation of the prepared films \\ Thickness and weight variation}

The thickness of the patch at three different points was determined using screw gauge and the patches were then weighed individually using digital balance to determine the weight of each patch taken out from the casted film. The patches were subjected to weight variation by individually weighing ten randomly selected patches. Such determinations were carried out for each formulation ${ }^{10}$.

\section{Folding endurance test}

Folding endurance test was carried out by folding the patch at the same point a number of times till it broke ${ }^{11}$. The test was carried out to check the efficiency of the plasticizer and the strength of the film prepared using various ratios of the polymers. The test was carried out in triplicate. 
Table 1: Composition of transdermal patches using Propranolol

\begin{tabular}{cccc}
\hline Formulation Code & Eudragit RS100 & HPMC K 100 M & PVP \\
\hline F 1 & 1.0 & 1.5 & 0.5 \\
F 2 & 1.0 & 0.5 & 1.5 \\
F 3 & 1.0 & 1.0 & 1.0 \\
F 4 & 1.0 & 2.0 & - \\
F 5 & 1.0 & - & 2.0 \\
F 6 & 1.5 & 1.5 & - \\
F 7 & 1.5 & - & 1.5 \\
F 8 & - & 1.5 & 1.5 \\
F 9 & 2.0 & 0.5 & 0.5 \\
F 10 & 2.0 & 1.0 & - \\
F 11 & 2.0 & - & 1.0 \\
\hline
\end{tabular}

Drug loaded in each film: Propranolol: $25 \mathrm{mg}$; Plasticizers: Propylene Glycol (30\% w/w of polymer); Backing membrane: Aluminium foil.

\section{Percentage moisture loss}

Accurately weighed films of each formulation were kept in a desiccator and exposed to an atmosphere of $98 \%$ relative humidity (containing anhydrous calcium chloride) at room temperature and weighed after 3 days $^{12}$. The test was carried out in triplicate. The percentage of moisture loss was calculated as the difference between initial and final weight with respect to initial weight.

\section{Percentage moisture uptake}

Accurately weighed films of each formulation were kept in a desiccator which is maintained at $79.5 \%$ relative humidity (saturated solution of aluminium chloride) at room temperature and weighed after 3 days ${ }^{13}$. The test was carried out in triplicate. The percentage of moisture uptake was calculated as the difference between final and initial weight with respect to initial weight.

\section{Water absorption capacity}

Three film units of each formulation were kept in an atmosphere of relative humidity, $\mathrm{RH}=82 \%$ for one week and the difference in weight of the film was taken as the water absorption capacity for that film ${ }^{14}$.

\section{Water vapor transmission rate}

For water vapor transmission studies glass vials of equal diameter were used as transmission celli5. These transmission cells were washed thoroughly and dried in an oven. About $1 \mathrm{gm}$ of anhydrous calcium chloride was taken in the cell and the polymer film was fixed over the brim with the help of the solvent. The cells were accurately weighed and kept in a closed desiccator containing saturated solution of potassium chloride to maintain a humidity of $84 \% \mathrm{RH}$. The cells were taken out and weighed after 1 , $2,3,4,5,6$ and $7^{\text {th }}$ day. Water vapor transmission (WVT) rate was usually expressed as the number of grams of moisture gain/hours/ sq.cm.

$$
\mathrm{WVT}=\mathrm{WL} / \mathrm{S}
$$

Where, $\mathrm{W}$ is water vapor transmitted in $\mathrm{mg}, \mathrm{L}$ is thickness of the film in $\mathrm{mm}, \mathrm{S}$ is exposed surface area in $\mathrm{cm}^{2}$.

\section{Drug content}

Films of specified area were cut and the pieces were taken into a $100 \mathrm{ml}$ volumetric flask containing Phosphate buffer ( $\mathrm{pH}$ 7.4), 
and the flask was sonicated for $8 \mathrm{~h}^{16}$. A blank was prepared in the same manner using a drug-free placebo patch of same dimensions. The solution was then filtered using a 0.45 $\mu \mathrm{m}$ filter and the drug content was analyzed at $289 \mathrm{~nm}$ by UV spectrophotometer.

\section{In-vitro drug release studies}

The in-vitro release studies were carried out by using Keshary chein apparatus. The receptor compartment was maintained at $37 \pm 1^{\circ} \mathrm{C}$ by means of a water bath, circulator, and a jacket surrounding the cell. The cells were filled with freshly prepared Phosphate buffer $\mathrm{pH}$ 7.4. The solution in the receptor compartment was continuously stirred at 60 rpm by means of Teflon coated magnetic stirrer, in order to avoid diffusion layer effects. The Commercial Semi-permeable membrane were mounted between the donor and receptor compartment and secured in place by means of a clamp. The patch was placed on one side of the semipermeable membrane ${ }^{17,18}$. Aliquots of $1 \mathrm{ml}$ were removed from the receptor compartment by means of a syringe and replaced immediately with the same volume of fresh buffer solution kept at $37 \pm 1^{\circ} \mathrm{C}$. Test samples were taken from the medium at predetermined time intervals over a period of 24 hours and the samples were analyzed for Propranolol content by UV spectrophotometer at 289 $\mathrm{nm}^{19}$. The diffusion kinetics of the Propranolol was analyzed by graphical method for zero order, Higuchi and Peppa's exponential equation.

\section{In-vitro Transdermal permeation}

The hairs of the male Wistar albino rat were cleared by using scissors. After cleaning the skin with Phosphate buffer $\mathrm{pH}$ 7.4, animal was sacrificed by excessive ether inhalation. An incision was made on the flank of the animal and the skin was separated. The prepared skin was washed with Phosphate buffer pH 7.4 and used.

Snake skin, ${ }^{20}$ offers considerable advantages over human material, as it is relatively abundant. In shed snake, the permeability coefficient of lipophilic drugs was in the same range as those through the human skin. Shed skin of "NAJA NAJA" was collected and soaked in pH 7.4 Phosphate buffer for half an hour and then used. The shed skin was mounted in such a way that the ventral surface side of the skin was kept intimate contact with the formulation and keeping the dorsal region of skin being contact with the release surface of the donor compartment.

Albino porcine ear, ${ }^{21}$ was obtained from a local slaughter house. The epidermis was prepared by a heat separation technique. The whole skin was soaked in water at $60^{\circ} \mathrm{C}$ for 45 seconds, followed by careful removal of the epidermis. The epidermis was washed with $\mathrm{pH}$ 7.4 Phosphate buffer and used.

The transdermal permeation was performed in Chein Diffusion cell. The cells were filled with freshly prepared Phosphate buffer $\mathrm{pH}$ 7.4. While placing the patch, the donor compartment contains patch on stratum corneum side of skin and dermis side was facing receptor compartment ${ }^{22}$. Receptor compartment contains Phosphate buffer $\mathrm{pH}$ 7.4 and samples were withdrawn at regular time intervals and replaced the same with receptor fluid. The samples were analyzed at $289 \mathrm{~nm}$ against blank by UV spectrophotometer ${ }^{23}$.

\section{In-vivo studies}

\section{Primary skin irritation test}

The dorsal part of rabbit was carefully shaved, and patch was applied on the shaved skin for 7 days. After the patch was removed, conditions of the dorsal skin were observed and are evaluated most often by modification described by Draize ${ }^{24}$ and his colleagues in 1944, which is based on scoring method. Scores as assigned from 0 to 4 based on the severity of erythema or oedema formation. The safety of the patch decreases with increase in scoring.

\section{Selection of animals}

Rabbit's (Crytolagus cuniculus) of male sex 10-12 weeks old weighing 1-2 kg were selected. They were kept with husk bedding and were fed with standard rodent pellet diet and water. Light \& dark cycles with 12 hours light and 12 hours dark were maintained. The temperature and relative humidity conditions were $28 \pm 2^{\circ} \mathrm{C}$ and $60 \pm 15 \%$ respectively. The 
protocols for all animal studies were approved by Institutional Ethical Committee (1220/a/08/CPCSEA).

\section{Method}

A set of healthy rabbits were selected. They were checked to ensure that they were free from disease. The dorsal surface of the selected rabbits was cleaned and hair was removed. The dose of Propranolol was calculated according to the body weight i.e., $3.2 \mathrm{mg}$ respectively ${ }^{25}$. The patch $\mathrm{F} 7(1.5 \%$ Eudragit RS 100, 1.5 \% HPMC K100M) was placed on the dorsal surface. At specific time interval the patch was removed from the rabbit carefully and analyzed for remaining drug content. Initial drug content was determined before placing the film. The remaining drug content was subtracted from the initial drug content of the film. The value obtained denotes the amount of drug in diffused from the patch into the body ${ }^{26}$.

\section{RESULTS AND DISCUSSION}

In the present work, efforts have been made to prepare transdermal drug delivery system of Propranolol using various blends of polymers such as Eudragit RS 100, Hydroxy Propyl methyl cellulose K100MNand Poly vinyl pyrrolidone. Permeation enhancer used was Propylene glycol.
The observed partition coefficients of Propranolol using n-octanol/Phosphate buffer pH 7.4 found to give log K values 3.16. The physicochemical compatibility of the drugs and the polymer was established through FTIR studies which have shown that there are no interactions. Physico-chemical evaluation data of table- 2 and 3 indicates that the thickness of the patches varied from $0.31 \pm 0.02$ to $0.40 \pm 0.04 \mathrm{~mm}$. Folding endurance values of matrix films were found within 291-343 folds, indicating good strength and elasticity. The drug content analysis and the weight uniformity of the prepared formulation have shown that the process adopted for casting the films in this investigation is capable of giving films with uniform drug content and with minimum intra batch variability. The percentage moisture uptake in the formulation $\mathrm{F} 11$ (1.5\% HPMC, $1.5 \%$ PVP) has shown the highest value of moisture absorption $9.44 \pm 0.02$ which may be due to higher polydispersity index and solubility parameter of HPMC, PVP. The formulation F $6(2 \%$ Eudragit RS 100, 0.5\% HPMC, 0.5\% PVP) shows higher value of moisture loss $10.78 \pm 0.01$ which may be due to presence of higher concentration of hydrophilic polymers and formulation F 11 (1.5\% HPMC, 1.5\% PVP) shows low value of $6.02 \pm 0.02$.

Table 2: Physicochemical evaluation of Propranolol transdermal patches

\begin{tabular}{cccccccc}
\hline $\begin{array}{c}\text { Formulation } \\
\text { Code }\end{array}$ & $\begin{array}{c}\text { Thickness } \\
\text { (mm) } \\
\pm \text { SD }\end{array}$ & $\begin{array}{c}\text { Weight } \\
\text { uniformity } \\
\pm \text { SD }\end{array}$ & $\begin{array}{c}\text { Folding } \\
\text { endurance } \\
\pm \text { SD }\end{array}$ & $\begin{array}{c}\text { \%moisture } \\
\text { loss } \\
\mathbf{\pm} \text { SD }\end{array}$ & $\begin{array}{c}\text { \%moisture } \\
\text { uptake } \\
\pm \text { SD }\end{array}$ & $\begin{array}{c}\text { Water vapour } \\
\text { transmission } \\
\text { rate } \\
\text { (g/cm } \mathbf{~} / \text { day) }\end{array}$ & $\begin{array}{c}\text { Drug } \\
\text { content } \\
\text { (\%) }\end{array}$ \\
\hline PP 1 & $0.33 \pm 0.01$ & $302.4 \pm 0.19$ & $321 \pm 3.1$ & $7.95 \pm 0.01$ & $8.28 \pm 0.02$ & $7.21 \times 10^{-3}$ & 99.59 \\
PP 2 & $0.39 \pm 0.05$ & $311.7 \pm 0.09$ & $343 \pm 2.1$ & $8.58 \pm 0.01$ & $7.98 \pm 0.01$ & $7.42 \times 10^{-3}$ & 99.23 \\
PP 3 & $0.39 \pm 0.04$ & $301.2 \pm 0.87$ & $331 \pm 1.8$ & $8.98 \pm 0.01$ & $8.77 \pm 0.03$ & $7.10 \times 10^{-3}$ & 98.62 \\
PP 4 & $0.31 \pm 0.02$ & $321.2 \pm 0.31$ & $298 \pm 2.7$ & $6.32 \pm 0.02$ & $9.43 \pm 0.01$ & $6.81 \times 10^{-3}$ & 99.30 \\
PP 5 & $0.40 \pm 0.04$ & $317.0 \pm 0.03$ & $297 \pm 1.2$ & $9.33 \pm 0.01$ & $7.32 \pm 0.03$ & $8.96 \times 10^{-3}$ & 98.32 \\
PP 6 & $0.36 \pm 0.02$ & $297.5 \pm 0.84$ & $312 \pm 2.3$ & $6.12 \pm 0.01$ & $9.44 \pm 0.02$ & $6.97 \times 10^{-3}$ & 98.90 \\
PP 7 & $0.38 \pm 0.08$ & $312.2 \pm 0.21$ & $291 \pm 1.1$ & $9.06 \pm 0.01$ & $7.38 \pm 0.04$ & $8.26 \times 10^{-3}$ & 99.11 \\
PP 8 & $0.35 \pm 0.07$ & $310.3 \pm 0.84$ & $311 \pm 2.6$ & $5.92 \pm 0.02$ & $10.31 \pm 0.01$ & $6.23 \times 10^{-3}$ & 98.77 \\
PP 9 & $0.36 \pm 0.02$ & $319.9 \pm 0.87$ & $325 \pm 2.6$ & $10.34 \pm 0.04$ & $6.26 \pm 0.03$ & $9.28 \times 10^{-3}$ & 98.58 \\
PP 10 & $0.35 \pm 0.01$ & $298.6 \pm 0.24$ & $312 \pm 2.8$ & $10.12 \pm 0.01$ & $6.76 \pm 0.01$ & $9.21 \times 10^{-3}$ & 99.36 \\
PP 11 & $0.38 \pm 0.04$ & $297.5 \pm 0.32$ & $317 \pm 1.9$ & $10.78 \pm 0.01$ & $6.02 \pm 0.02$ & $9.61 \times 10^{-3}$ & 98.52 \\
\hline
\end{tabular}

a: Mean \pm SD; $n=3$ 
The formulation $\mathrm{F} 11$ (1.5\% HPMC, 1.5\% PVP) has shown maximum water vapor transmission of $9.61 \times 10^{-3}$ among all the patches which may be due to presence of higher concentration of hydrophilic polymers and $\mathrm{F} 4$ has less water vapor transmission of $6.81 \times 10^{-3}$. The in-vitro release plots of all other formulations were suggestive of zero order release and are diffusion mediated which was confirmed from the regression value of Higuchi's plot. All the formulations undergo non-fickian type of release which is confirmed from the slope values obtained from the Peppa's plot.

The cumulative percentage of drug released in $24 \mathrm{~h}$ was found to be the highest for formulation F 7 (1.5 \% Eudragit RS 100, $1.5 \%$ HPMC) which has shown the drug release of 99.21\%. The in-vitro drug release plot indicates that the drug release followed zero order kinetics, which was evinced from the regression value (0.993) of the above mentioned plot. The Higuchi's plot has shown the regression value of 0.997 . In order to confirm this fact, Peppa's plot was drawn which has shown slope value of 0.452 . Hence formulation $\mathrm{F} 7$ was selected as the optimized formulation by virtue of its drug release kinetics. In-vitro transdermal permeation study was carried out in rat skin, snake shed skin and porcine ear skin the formulation $\mathrm{F} 7$ (1.5 \% Eudragit RS 100, 1.5 \% HPMC) showed drug diffusion for 24 hours up to the extent of 98.29\%, 98.56\% and $95.23 \%$ respectively. The comparative in-vitro drug diffusion data has been illustrated in Fig. 1. The variation among the used biological membrane could be attributed to the fat content and thickness of the membrane used. The result obtained from the primary skin irritation studies revealed that neither the adhesive nor the drug Propranolol, caused any noticeable irritation on the rabbit skin throughout the study. In-vivo study was carried out in rabbit, at the end of $24^{\text {th }}$ hour the in-vivo drug release showed $97.21 \%$. The results which are illustrated in Fig. 2 indicated that the in-vitro and in-vivo correlation was very good which reveals the reproducibility of drug release even in biological environment.

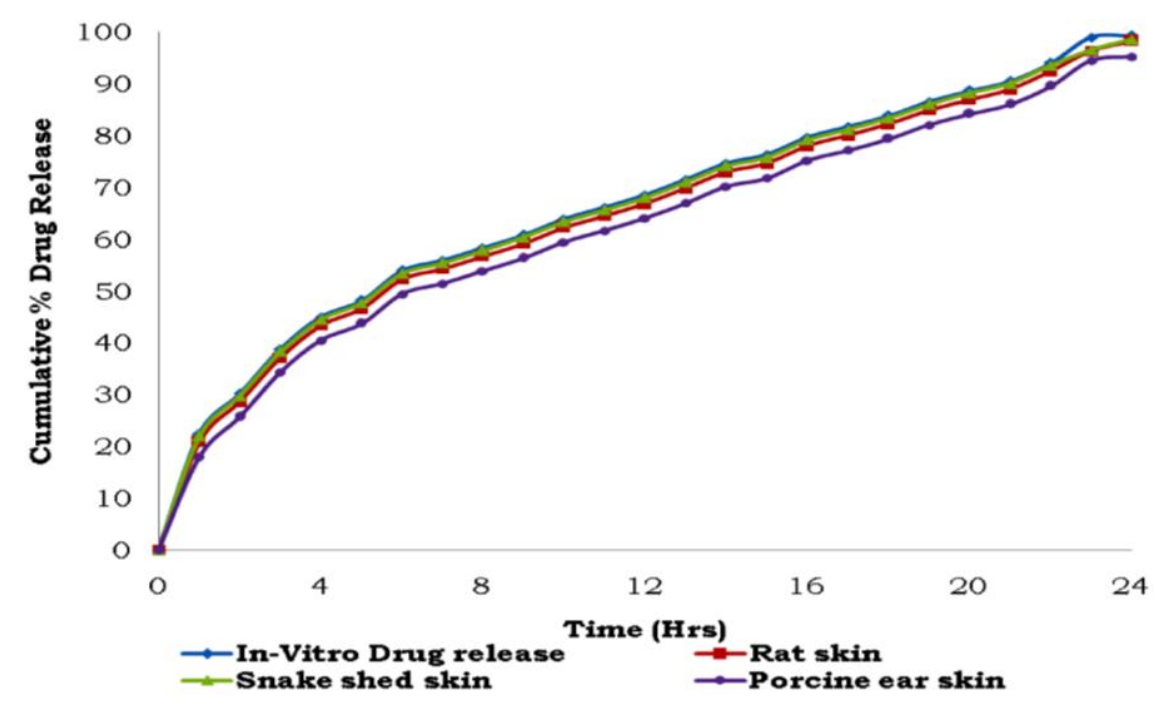

Fig. 1: Comparative In-vitro drug diffusion through artificial semipermeable membrane and various biological skins 


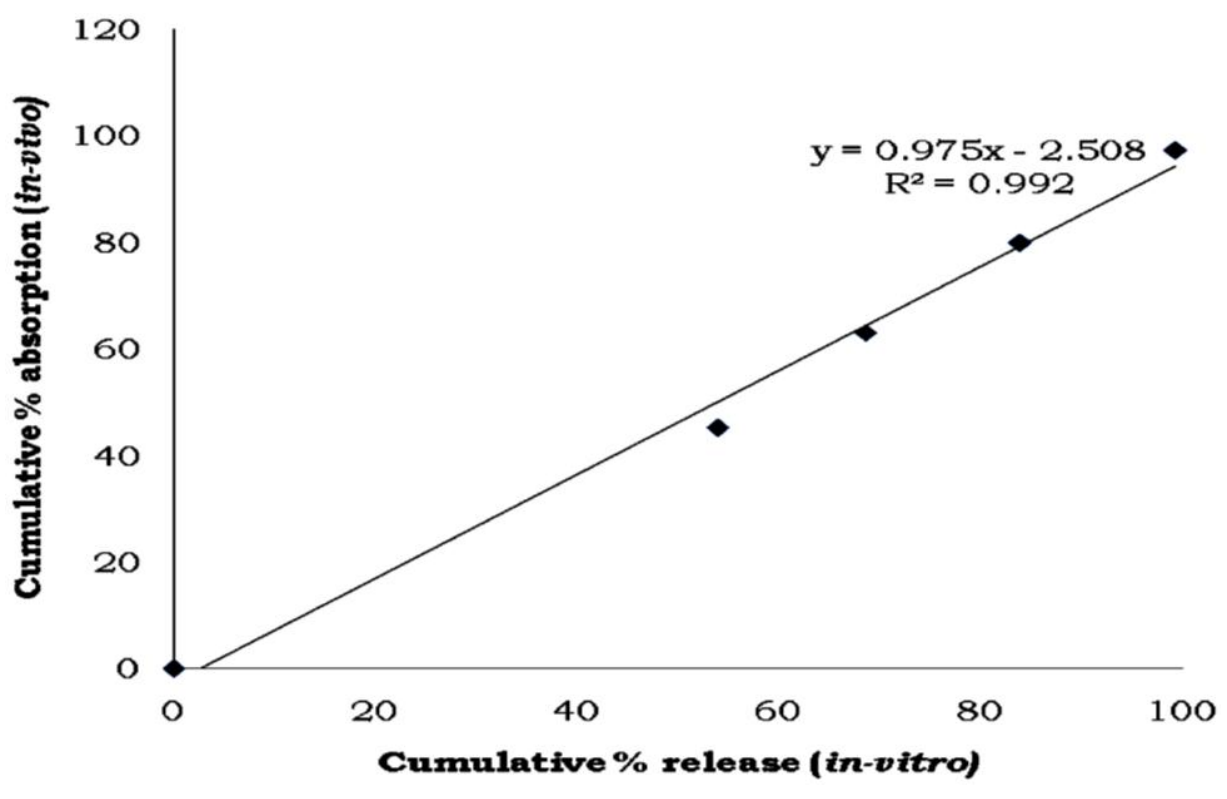

Fig. 2: In-vitro In-vivo Correlation of F 7

\section{CONCLUSION}

In conclusion, formulation $\mathrm{F} \quad 7 \quad(1.5 \%$ Eudragit RS 100, $1.5 \%$ HPMC K100M) has achieved the targets of present study such as controlled release, prolonged zero order release, reduced frequency of administration, greater therapeutic effect, overcome the side effects, simplify the treatment regimen and thus may improve patient compliance.

\section{REFERENCES}

1. D.J. Kazierad, K.D. Schlanz, M.B. Bottorf, Beta blockers, in: W.E. Evans, J.J. Schlentag, W.J. Jusko (Eds.), Applied Pharmacokinetics, Principle of Therapeutic Drug Monitoring, $3^{\text {rd }}$ Edition, Applied Therapeutics, 1992, 24-41.

2. Young-Chang Ah, Jin-Kyu Choi, Yang-Kyu Choi, Han-Moi Ki, Joon-Ho Bae. A novel transdermal patch incorporating meloxicam: In vitro and in vivo characterization. Int. J. Pharm., 2010; 385(1-2): 12-19.

3. Modamio P, Lastra CF, Marino EL. A comparative in vitro study of percutaneous penetration of betablockers in human skin. International Journal of Pharmaceutics, 2000; 194: 249259.

4. Ranade VV. Drug delivery systems. Transdermal drug delivery. Journal of
Clinical Pharmacology, 1991; 31: 401418.

5. Changshun Rena, Liang Fanga, Lei Ling, QiangWang, Sihai Liu, LiGang Zhao, Zhonggui He. Design and in vivo evaluation of an indapamide transdermal patch. International Journal of Pharmaceutics, 2009; 370: 129-135.

6. Marin EL, Modamio P. Transdermal absorption of celiprolol and bisoprolol in human skin in vitro. International Journal of Pharmaceutics, 1998; 173: 141-148.

7. McDaid DM, Deasy DM. An investigation into the transdermal delivery of nifedipine. Pharmaceutica Acta Helvetiae, 1996; 71: 253-258.

8. Jagmohan. Organic Spectroscopy. Edn 2, Narosa Publications, Inc., New Delhi, 2003; 212-232.

9. Posina Anitha, Sundarapandiyan Ramkanth, Mohamed T S Saleem, Kommireddy Umasankari, Boddu Praveen Reddy, Madhusudhana Chetty. Preparation, in-vitro and in-vivo characterization of transdermal patch containing glibenclamide and Propranolol: a combinational approach. Pakistan Journal of Pharmaceutical Sciences, 2011; 24(2): 155-163.

10. Mundada AS, Avari JG. Damar Batu as a novel matrix former for the transdermal drug delivery: in-vitro evaluation. Drug 
Development and Industrial Pharmacy, 2009; 35: 1147-1154.

11. Ubaidulla U, Reddy MVS, Ruckmani K, Ahmed FJ, Khar RK. Transdermal therapeutic system of carvedilol: Effect of hydrophilic and hydrophobic matrix on in vitro and in vivo characteristics. AAPS PharmSciTech, 2007; 8: 1-8.

12. Kusum Devi V, Saisivam S, Maria GR, Depti PU. Design and Evaluation of Matrix diffusion Controlled Transdermal patches of Verapamil Hydrochloride. Drug Development and Industrial Pharmacy, 2003; 29: 495 - 503.

13. Biswajit Mukherjeea, Sushmita Mahapatraa, Ritu Guptab. Comparison between povidone-ethyl cellulose and povidone-Eudragit transdermal Dexamethasone matrix patches based on in vitro skin permeation. European Journal of Pharmaceutics and Biopharmaceutics, 2005; 59: 475-483.

14. Udupa N, Koteshwar KB, Vasantha Kumar. Formulation and Evaluation of Captopril Transdermal preparations. Indian Drugs, 1992; 29: 680 - 85.

15. Kulkurni Raghavendra, Doddaya $H$, Marihal SC, Patiln CC, Habhu PV. Comparative evaluation of polymeric films for transdermal application. The Eastern Pharmacist, 2000; 516: 109 - 111.

16. Mazzo DJ, Obetz CL, Shuster J, Brittain HG. Analytical profiles of drug substances and excipients. San Diego CA: Academic Press Inc. 1994; 23: 53.

17. Ji-Hui Zhao, Ji-Hua Fu, Shu-Ming Wang. A novel transdermal patch incorporating Isosorbide dinitrate with Bisoprolol: In vitro and In vivo characterization. International Journal of Pharmaceutics, 2007; 337: 88-101.

18. Yanli Gao, Jinying Liang. Double-layer weekly sustained release transdermal patch containing gestodene and ethinylestradiol. International Journal of Pharmaceutics, 2009; 377: 128-134.

19. Vlassios Andronis, Mounir S. Mesiha. Design and evaluation of transdermal Chlorpheniramine maleate drug delivery system. Pharmaceutics Acta Helvetiae 1995; 70: 301-306.

20. Hatanaka T, Panomsuk S, Opanasopit P, Rojanarata T. Comparison of the percutaneous absorption of hydrophilic and lipophilic compounds in snake shed skin and human skin. Pharamzie, 2006; 61: $331-335$.

21. Jagadish Singh, Kaidi Zha. In-vitro percutaneous absorption enhancement of Propanolol $\mathrm{HCl}$ through Porcine epidermis by Terpenes/ethanol. Journal of Control Release, 1999; 62: 359 - 366.

22. Ke GM, Wang L, Xue HY, Lu WL, Zhang X, Zhang $Q$, Guo HY. In vitro and In vivo characterization of a newly developed Clonidine transdermal patch for treatment of attention deficit hyperactivity disorder in children. Biological and Pharmaceutical Bulletin, 2005; 28: 305-310.

23. Srinivas Mutalik, Nayanabhirama Udupa, Sharath Kumar, Sunil Agarwal, Ganesh Subramanian, Averineni K. Ranjith. Glipizide matrix transdermal systems for diabetes mellitus: Preparation, in-vitro and preclinical studies. Life Sciences, 2006; 79: 1568-1577.

24. Draize JH, Woodard G, Calvery HO. Methods for the study of irritation and toxicity of substances applied topically to the skin and mucous membranes, Journal of Pharmacology and Experimental Therapeutics, 1944; 82: 377-390.

25. Jayaprakash S, Mohamed Halith S, Mohamed Firthouse PU. Preparation and evaluation of celecoxib transdermal patches. Pakistan Journal of Pharmaceutical Sciences, 2010; 23(3): 279-283

26. Chakkapan S, Kiran Gandhi, Suja Thomas, Katkam RR, Puri CP, Srivastava R. Studies in transdermal drug delivery system for estradiol. Indian Journal of Pharmaceutical Sciences, 1994; 56(4): 121-125. 